\title{
PENDAMPINGAN PROGRAM ALIH TEKNOLOGI MESIN PEMOTONG SAYURAN UNTUK PENINGKATAN USAHA KUE TRADISIONAL YANG BERKUALITAS
}

\section{ASSISTANCE OF TECHNOLOGY TRANSFER PROGRAM FOR VEGETABLE CUTTING MACHINE TO IMPROVE THE QUALITY OF TRADITIONAL CAKES}

\author{
Oleh: \\ Yovan Witanto $^{1)}$,Hendra $^{\text {I) }}$, Anizar Indriani ${ }^{2)}$ \\ ${ }^{1)}$ Program Studi Teknik Mesin, Fakultas Teknik, Universitas Bengkulu \\ ${ }^{2)}$ Program Studi Teknik Elektro, Fakultas Teknik, Universitas Bengkulu \\ Email:yovanmail@ymail.com
}

\begin{abstract}
Pematang Gubernur, Muara Bangkahulu District, Bengkulu City, is a town where many people do small business making and selling traditional cakes or fried foods. This business uses vegetables, such as potato, carrot, cabbage as base ingredients. However, the people have not yet used technology to help them do the work, especially for the vegetable cutting process. Hence, they lack of time efficiency and consistency in size of the cut food. To overcome this, technology is needed in the form of a multipurpose vegetable cutting machine capable of cutting large capacity vegetables in no time. This community service activity aims to assist technology transfer programs to the community. The team of this program introduces the vegetable cutting machines, as well as providing and motivating ways to create, install and use vegetable cutting machines. Methods used in this program include assisting in the identification of vegetable / grass cutting machine components, design assistance, material selection and manufacturing of cutting machines and practice using cutting machines. The results show that participants are very interested in making and using the equipment. They expect the sustainability of this activity. Participants hope that this activity will be continued with training in making various forms of vegetable cutting mold. Different shapes of cutting is expected to get more attractive look of the food.
\end{abstract}

Keywords: Vegetables, Small Business, Vegetable Cutting machines

\section{PENDAHULUAN}

Teknologi mesin pemotong sayuran/umbi-umbian untuk pembuatan kue basah/gorengan akan mengurangi waktu pemotongan, meningkatkan kualitas pemotongan dan kapasitas pemotongan yang lebih baik. Mesin pemotong sayur ini dapat meningkatkan efisiensi kerja pelaku usaha kue basah hingga 98\%. Para pelaku usaha hanya membutuhkan waktu 30 menit untuk memotong wortel sebanyak $3 \mathrm{~kg}$. Dibandingkan dengan cara manual, dengan menggunakan alat ini para pelaku usaha dapat mengurangi anggaran pengerjaan memotong wortel.

Masyarakat Kelurahan Pematang Gubernur Kecamatan Muara Bangkahulu Kota Bengkulu termasuk yang memanfaatkan sayuran/umbi-umbian untuk usaha kecilnya dalam membuat kue basah/gorengan. Proses pengolahan sayur/umbi-umbian untuk pembuatan kue basah masih dilakukan secara manual. Pemanfaatan mesin pemotong sayuran yang sederhana dan mudah digunakan belum termanfaatkan secara baik.Hal ini disebabkan oleh kekurang tahuan masyarakat terhadap pemanfaatan 
mesin pemotong sayuran yang mampu membuat sayuran dengan waktu yang singkat, kapasitas yang banyak, kualitas dimensi/ukuran yang konstan, dan mudah dibuat. Masyarakat Kelurahan Pematang Gubernur Kecamatan Muara BangkahuluKota Bengkulu ini memerlukan motivasi dan pelatihan dalam alih teknologi pemanfaatan mesin pemotong sayuran/umbi-umbian agar dapat digunakan untuk meningkatkan produktifitas produksi kue basah/gorengan. Dengan demikian dalam pengabdian masyarakat ini akan dilakukan Pendampingan Program Alih Teknologi Mesin Pemotong Sayuran untuk Peningkatan Usaha Kue Basah/Gorengan yang Berkualitas di Kelurahan Pematang Gubernur Kecamatan Muara Bangkahulu Kota Bengkulu. Pendampingan Alih teknologi dilakukan dengan memberikan pelatihan perancangan, pembuatan dan pengujian mesin pemotong sayuran untuk usaha kue basah/gorengan dengan kualitas terukur. Hasil potongan sayuran yang terukur ini diharapkan produktifitas produksi kue basah dari pemanfaatan sayuran/umbi-umbian sebagaibahan dasar kue basah/gorengan dapat ditingkatkan sehingga kualitas hasil kue basah/gorengan yang baik dapat diperoleh dan menambah nilai ekonomis bagi masyarakat usaha kecil

Mesin pemotong/pengiris/perajang merupakan suatu unit operasi utnuk memperkecil dimensi/ukuran hasil pengolahan pascapanen komoditi umbi-umbian dan buah-buahan. Pengecilan ukuran berfungsi untuk mempermudah proses pendistribusian, pengeringan, penggorengan, difusi dan lainnya. Mesin pemotong sayuran dapat dilihat pada proses pemotongan bawang merah (Efendi, 2018, Tantan, 2010), pengirisan kentang (Pangihutan, 2016, Mungkur, 2015), pengirisan ubi (Lutfi, 2010, Saputra, 2012), dan lainnya.

Mekanisme pemotongan/pengirisan sayuran/umbian meliputi pengirisan screw mekanis, pengirisan slider dan mesin perajang sederhana. Bentuk mesin dengan pengirisan screw dapat dilihat pada Gambar 1. Untuk mesin pengirisan slider dan perajang sederhana dapat dilihat pada Gambar 2.Komponen mesin pemotong ini meliputi rangka, motor, pulley, pisau pemotong, poros, bantalan, V-Belt dan lainnya. Kinerja mesin pemotong dipengaruh loleh kinerja komponen tersebut dan juga tergantung pada kapasitas mesin pemotong yang akan dibuat (Sularso, 2013, Stock, 1994, Sigley, 1994).

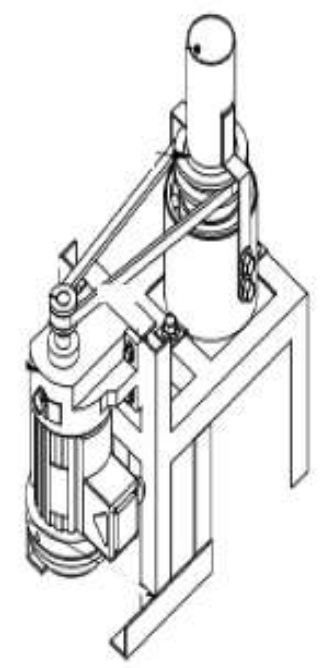

Gambar 1. Mesin Pengiris Kentang Screw Mekanis (Pangihutan, 2016) 

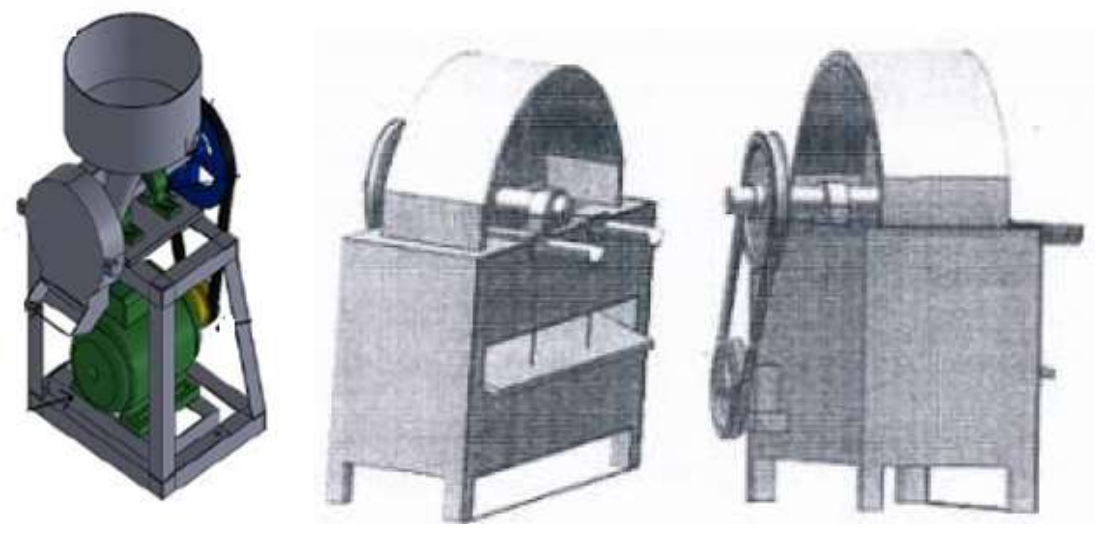

Gambar 2. Mesin Pengiris Dan Perajang Sayurang Yang Sederhana (Efendi, 2018 dan Sajuli, 2017)

Masyarakat Kelurahan Pematang Gubernur Kecamatan Muara Bangkahulu Kota Bengkulu termasuk daerah yang sangat memanfaatkan sumber daya alam seperti sayuran dan umbi-umbian ini sebagai mata pencaharian (perekonomian) masyarakat yaitu pembuat kue basah/gorengan. Permasalahannya adalah hampir sama dalam hal pengolahan atau proses pemanfaatan sayuran/umbiumbian masih dilakukan secara manual. Dalam proses secara manual ini masih memiliki kendala yaitu waktu proses pemotongan yang lama, membutuhkan tenaga yang banyak, kualitas pemotongan yang tidak sama dan merata dan higienis proses pemotongan yang kurang terjaga. Untuk itu dalam pengabdian pada masyarakat pembinaan ini sudah dilakukan pengenalan penggunaan mesin pemotong sayuran/umbiumbian untuk proses pengolahan bahan dasar kue basah.

Tujuan kegiatan ini adalah untuk pendampingan program alih teknologi kepada masyarakat Kelurahan Pematang Gubernur Kecamatan Muara Bangkahulu Kota Bengkulu dalam :

1. Menjelaskan mesin pemotong sayuran untuk bahan dasar kue basah/gorengan untuk usaha kecil.

2. Membuat dan merakit mesin pemotong sayuran untuk bahan dasar kue basah/gorengan dan lainnya.

3. Menggunakan alat mesin pemotong sayuran untuk bahan dasar kue basah/gorengan dalam waktu yang cepat dengan ukuran yang sama sehingga menghasilkan kualitas kue basah/gorengan yang baik.

\section{METODE PENGABDIAN}

Pola pelaksanaan program pengabdian masyarakat ini adalah pendampingan dengan sosialisasi, presentasi dan pelatihan melalui pemberdayaan masyarakat di Kelurahan Pematang Gubernur Kecamatan Muara BangkahuluKota Bengkulu.Untuk proses awal dilakukan pengenalan komponen mesin pemotong sayuran/umbi-umbian untuk pembuatan kue basah/gorengan, manfaat dan prinsip kerja mesin pemotong sayuran. Kemudian penjelasan pembuatan danperakitan komponen hingga menjadi mesin pemotong sayuran/umbi-umbian yang sederhana, mudah dibuat dan bahan baku yang dapat ditemukan dan murah. Mesin pemotong dapat dilihat pada Gambar 3. 
Faktor-faktor yang harus diperhatikan dalam pembuatan mesinpemotong sayuran/umbi-umbian adalah:

1. Pemilihan bahan mesin potong dan proses pemotong sayuran/umbi-umbian.

2. Mekanismenya pembuatan yang sederhana dan ringan.

3. Ongkos pembuatan dan perawatan lebih murah dan material komponennya mudah diperoleh.

4. Mudah dalam pengoperasiannya.

Untuk menanggulangi permasalahan tentang pembuatan mesinpemotong sayuran/umbiumbianini maka dilakukan pendampingan pembuatan mesinpemotong sayuran/umbi-umbian yang sederhana, murah dan mudah dibuat. Tahapan pelatihannya meliputi:

1. Pendampingan pengenalan komponen mesin pemotong sayuran/umbi-umbian untuk pembuatan kue basah/gorengan.

Proses pendampingan pelatihan pembuatan mesin pemotong sayuran/umbi-umbian untuk pembuatan kue basah/gorengan diawali dengan pengenalan komponen mesinpemotong yang dapat dilihat pada Gambar 3yaitu :

a. Rangka dudukan mesin pemotong sayuran/umbi-umbian untuk pembuatan kue basah/gorengan.

b. Pisau pemotong.

c. Pully

d. Motor penggerak pisau pemotong (motor dapat diganti dengan tenaga dorong lainnya seperti kincir air).

2. Pendampingan perancangan, pemilihan bahan dan pembuatan mesin pemotong sayuran/umbi-umbian untuk pembuatan kue basah/gorengan.

Prosedur pendampingan pelatihan perancangan, pemilihan bahan dan pembuatan mesin pemotong sayuran/umbi-umbian untuk pembuatan kue basah/gorengan ini meliputi:

1. Pendampingan perancangan, pemilihan bahan dan pembuatan mesin pemotong sayuran/umbi-umbian untuk pembuatan kue basah/gorengan.

2. Pengujian mesin pemotong sayuran/umbi-umbian untuk pembuatan kue basah/gorengan dengan pemaanfaatan sayuran/umbi-umbian seperti wortel, kol dan lainnya.

3.

Partisipasi mitra adalah:

1. Peserta yang akan mengikuti pelatihan ini berdasarkan rekomendasi dari Lurah.

2. Memberikan motivasi kepada masyarakat untuk mengikuti pelatihan, mengawasi dan pembina selama mengikuti kegiatan pelatihan.

3. Pada tahap pembuatan mesin pemotong sayuran/umbi-umbian untuk pembuatan kue basah/gorengan mitra selalu ikut berpartisipasi dalam setiap kegiatan. 


\section{Praktek penggunaan mesin pemotong sayuran/umbi-umbian untuk pembuatan kue} basah/gorengan.

Prosedur praktek kerja mesin pemotong sayuran/umbi-umbian untuk pembuatan kue basah/gorengan yang dibuat adalah:

1. Mempersiapkan semua alat dan mesin pemotong sayuran/umbi-umbian untuk pembuatan kue basah/gorengan.

2. Memasukan sayuran/umbi-umbian berupa wotel, kol dan lainnya yang akan dipotong dan diolah menjadi bahan dasar kue basah/gorengan.

3. Menghidupkan motor penggerak dan menggerakan komponen yang memiliki pisau pemotong.

4. Memotong sayuran/umi-umbian dan mengukur dimensi potongan sayuran/umbi-umbian tersebut.

5. Mengukur lamanya waktu pemotongan dan kapasitas pemotongan.

\section{Evaluasi dari partisipasi mitra adalah:}

1. Sebelum pelatihan dimulai, mitra mempersiapkan sayuran/umbi-umbian yang akan dipotong.

2. Setelah pelatihan, mitra akan mengukur waktu dan kapasitas sayuran/umbi-umbian yang sudah terpotong.

3. Membandingkan hasil pemotongan dan pengukuran kualitas dari prosesmanual dan menggunkan mesin potong.

Mesin pemotong sayuran/umbi-umbian untuk pembuatan kue basah/gorengan memiliki beberapa komponen seperti rangka dudukan pemotong, pisau pemotong, piringan pemutar pisau-pisau pemotong, pully dan rumah pemotong. Komponen dan dimensi mesin pemotong sayuran/umbi-umbian untuk pembuatan kue basah/gorengandapat dilihat pada Gambar 3. 


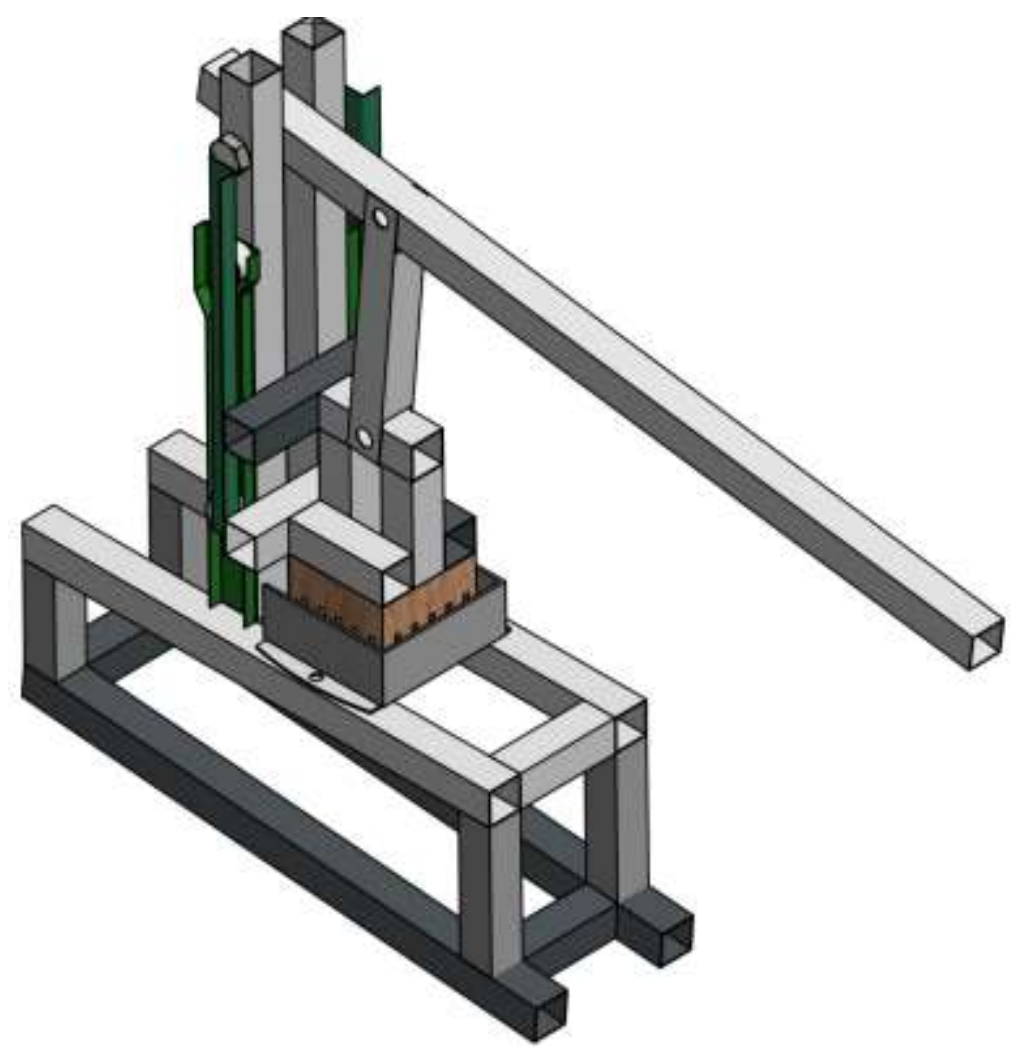

Gambar 3. Mesin Pemotong Sayuran Untuk Bahan Dasar Kue Basah/Gorengan

\section{HASIL DAN PEMBAHASAN}

Kegiatan ini diawali dengan penjajagan awal, yakni pertemuan dengan bapak lurah Pematang Gubernur untuk kesepakatan diadakan kegiatan ini. Hasil penjajagan ini berupa kesedian bapak lurah Pematang Gubernur untuk diadakan kegiatan pendampingan program alih teknologi mesin pemotong sayuran untuk peningkkatan usaha kue basah/gorengan yang higienis dan berkualitas di kelurahn pematang gubernur kecamatan muara bangkahulu kota Bengkulu. Surat Kesediaan sebagai Mitra Pengabdian Kepada Masyarakat lurah Pematang Gubernur untuk menyetujui dilaksanakan kegiatan ini dapat dilihat pada lampiran 1 .

Hari kedua diadakan diskusi dengan bapak lurah dan beberpa calon peserta yang direkomendsikan oleh bapak lurah seperti terlihat pada gambar 4 


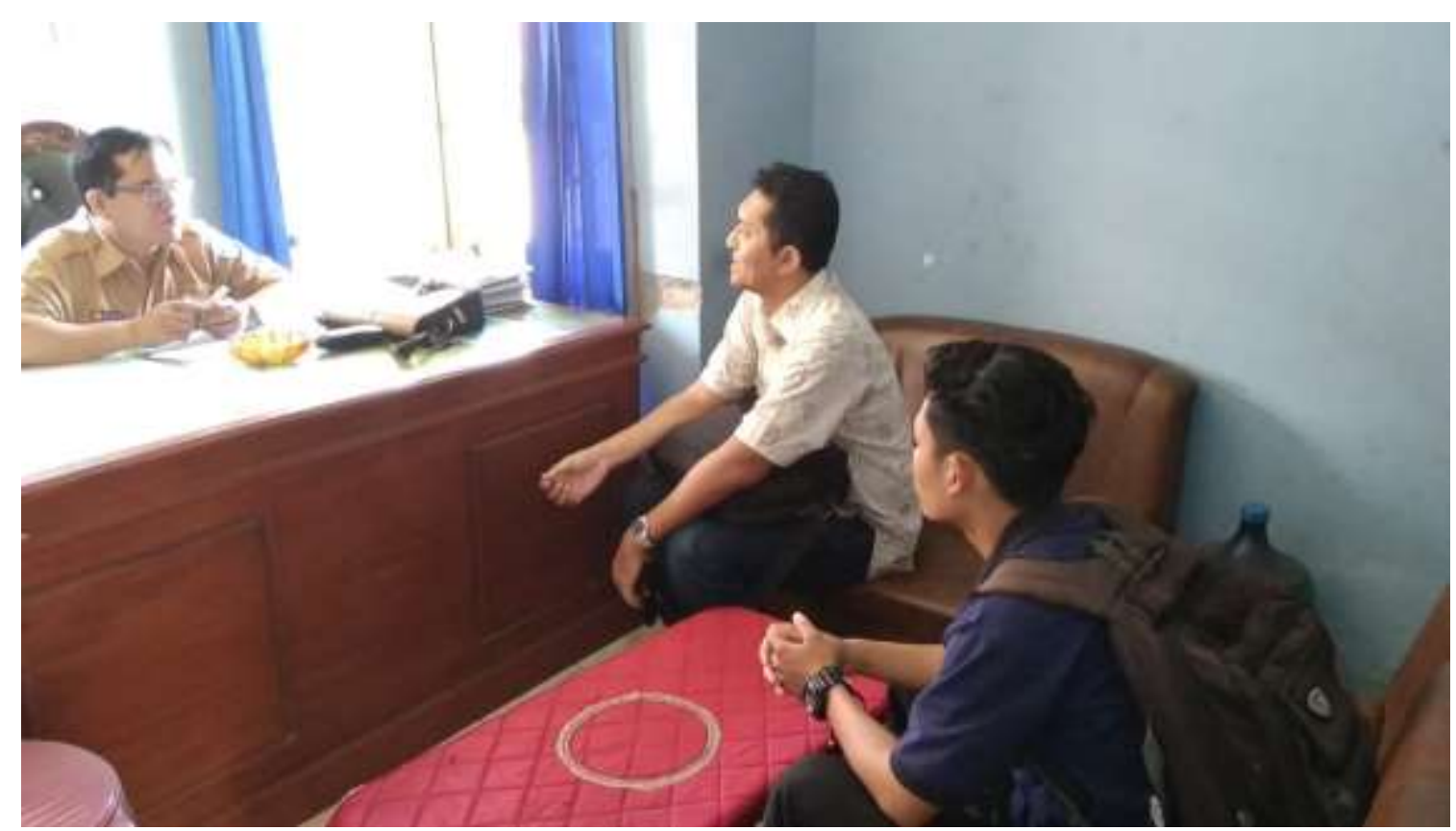

Gambar 4. Diskusi dengan Bapak Lurah dan Calon Peserta yang direkomendasikan oleh Bapak Lurah

Kegiatan ini menghasilkan kesepakatan bahwa peserta kegiatan adalah LPM kelurahan Pematang Guburnur, warga penjual kue basah/gorengan di RT.05, RT.35 dan RT.18 di kelurahan Pematang Gubernur

Hari ketiga, Kegiatan ini dilaksanakan,diawali dengan pembukaan, yang dilakukan oleh bapak lurah Pematang Gubernur, kecamatan Muara Bangkahulu, seperti terlihat pada gambar 5.

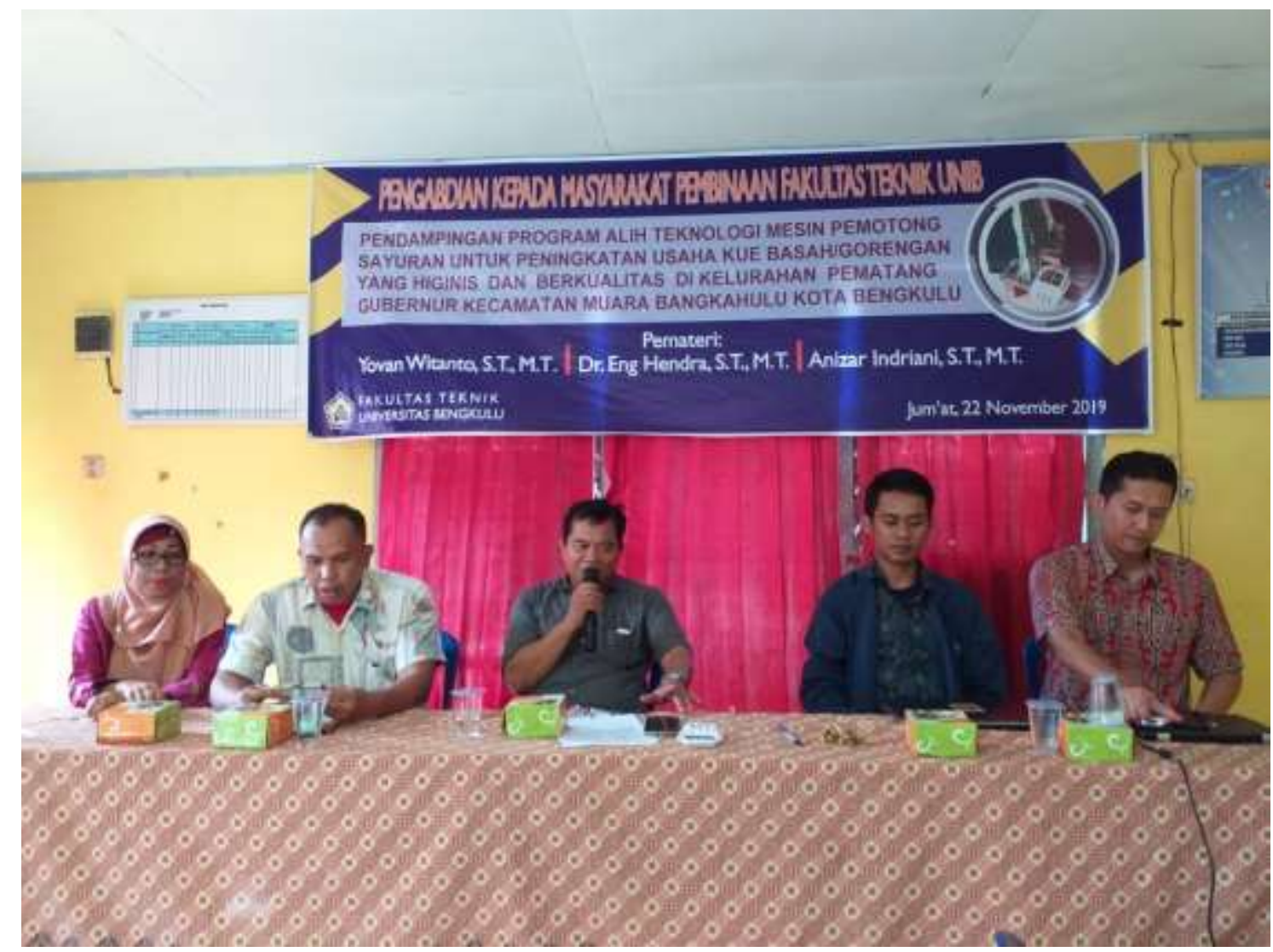

Gambar 5.Pembukaan Acara oleh Lurah Pematang Gubernur 
Kemudian dilanjutkan dengan sesi pertama yakni presentasi penyampaian materi dengan power point dan video. Kegiatan tersebut seperti terlihat pada gambar 6

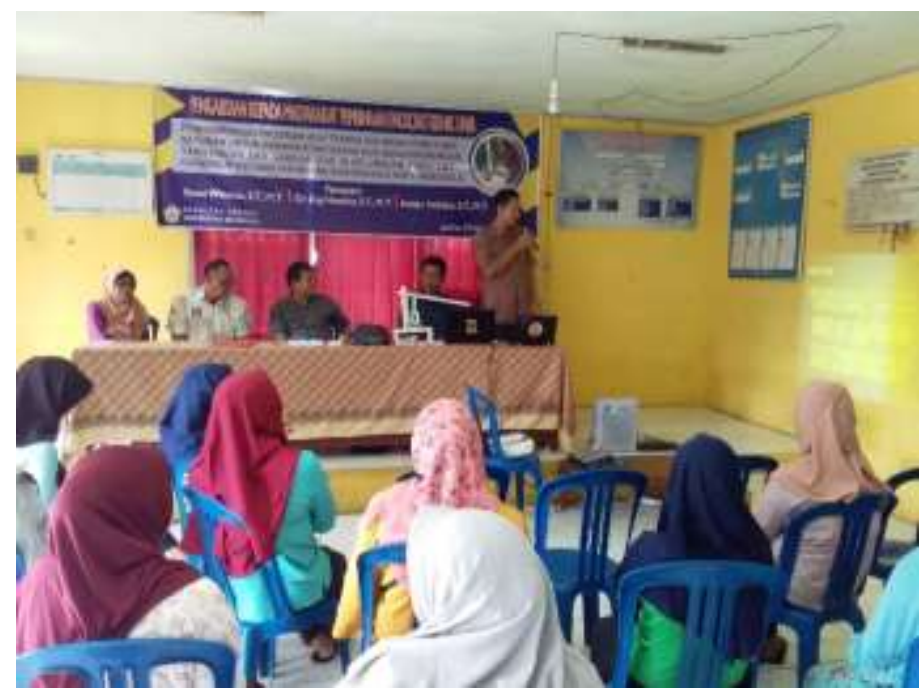

Gambar 6. Penyampaian Materi oleh Ketua Pengabdian

Setelah sesi pertama berakhir diadakan Tanya jawab dengan peserta. Hasil Tanya jawab menunjukkan bahwa mereka cukup faham dengan materi yang akan di praktekkan dan diuji cobakan pada sesi kedua.

Sesi kedua diawali dengan pengenalan komponen mesin pemotong sayuran/umbi-umbian untuk pembuatan kue basah/gorengan seperti terlihat pada gambar 7. Kemudian dilanjutkan dengan penjelasan pembuatan dan perakitan komponen hingga menjadi mesin pemotong sayuran/umbi-umbian yang sederhana, mudah dibuat dan bahan baku yang dapat ditemukan dan murah.

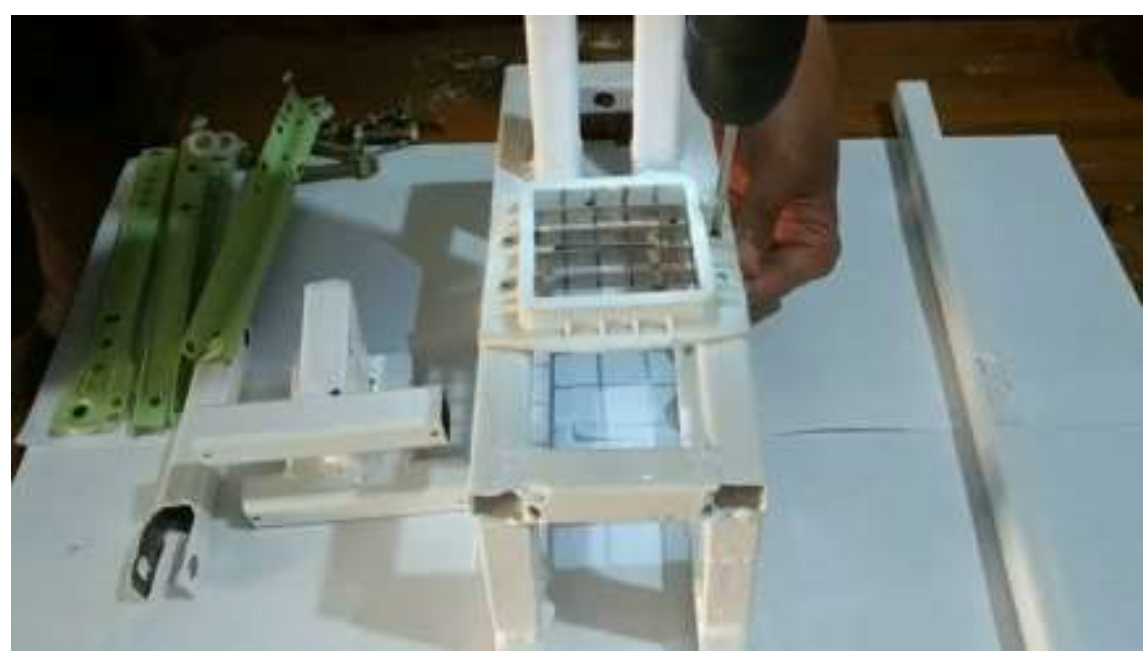




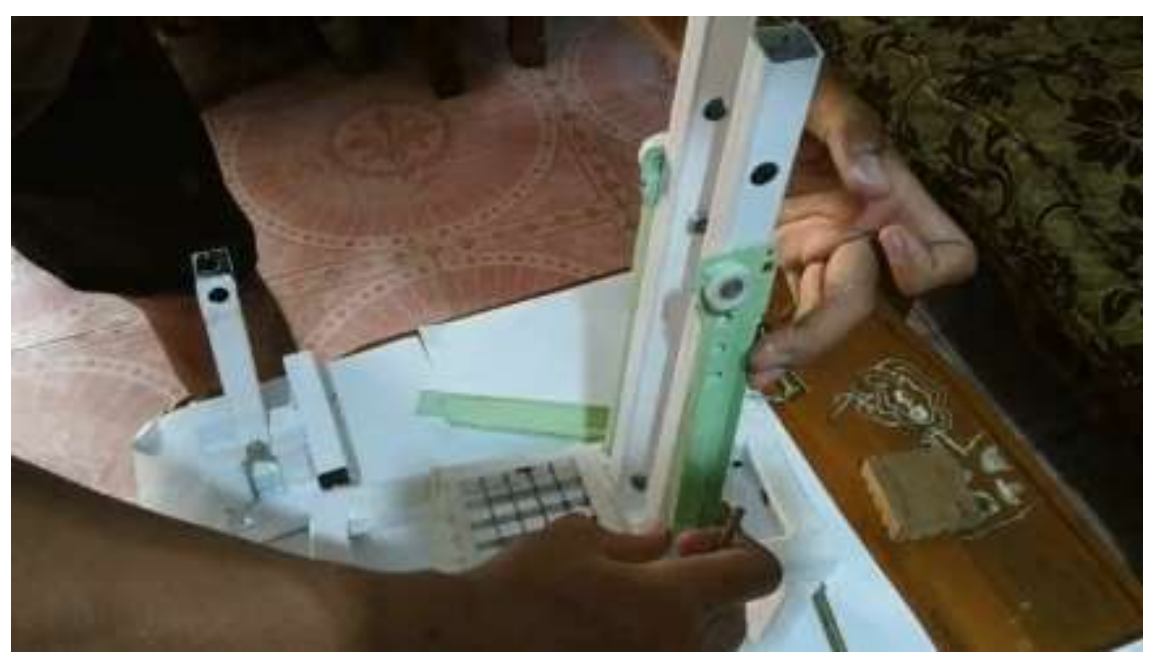

Gambar 7. Pengenalan Komponen dan Perakitan alat

Sesi ketiga dimulai setelah peralatan selesai dirakit. Alat yang sudah jadi seperti terlihat pada gambar 8

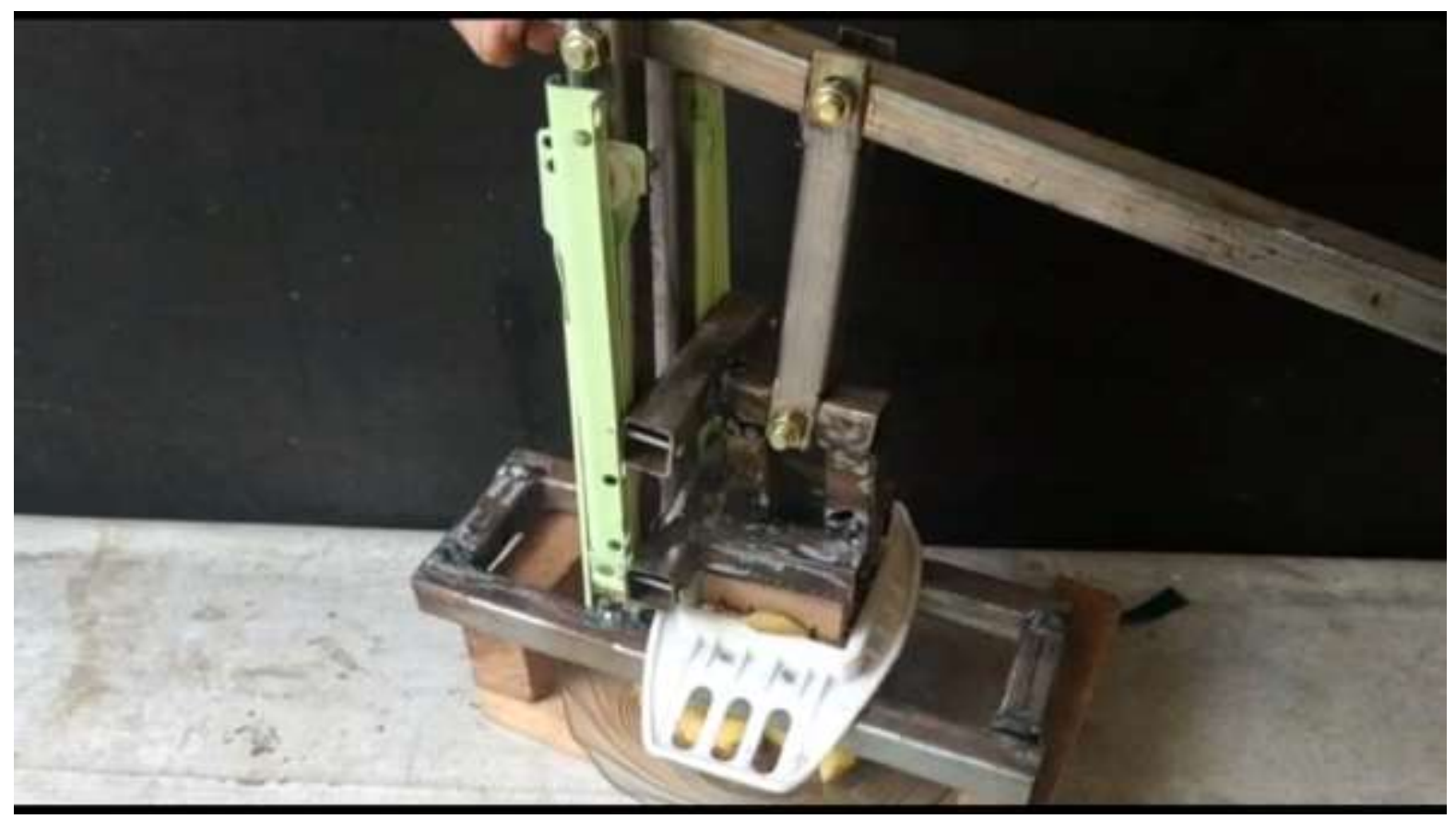

Gambar 8. Mesin Pemotong Sayuran/Umbi yang sudah siap

Kegiatan dilakukan dengan demo pengoperasian alat seperti terlihat pada gambar 9. Para peserta yang telah berhasil merakit peralatan tersebut diajarkan untuk menggunakan alat dengan benar. 


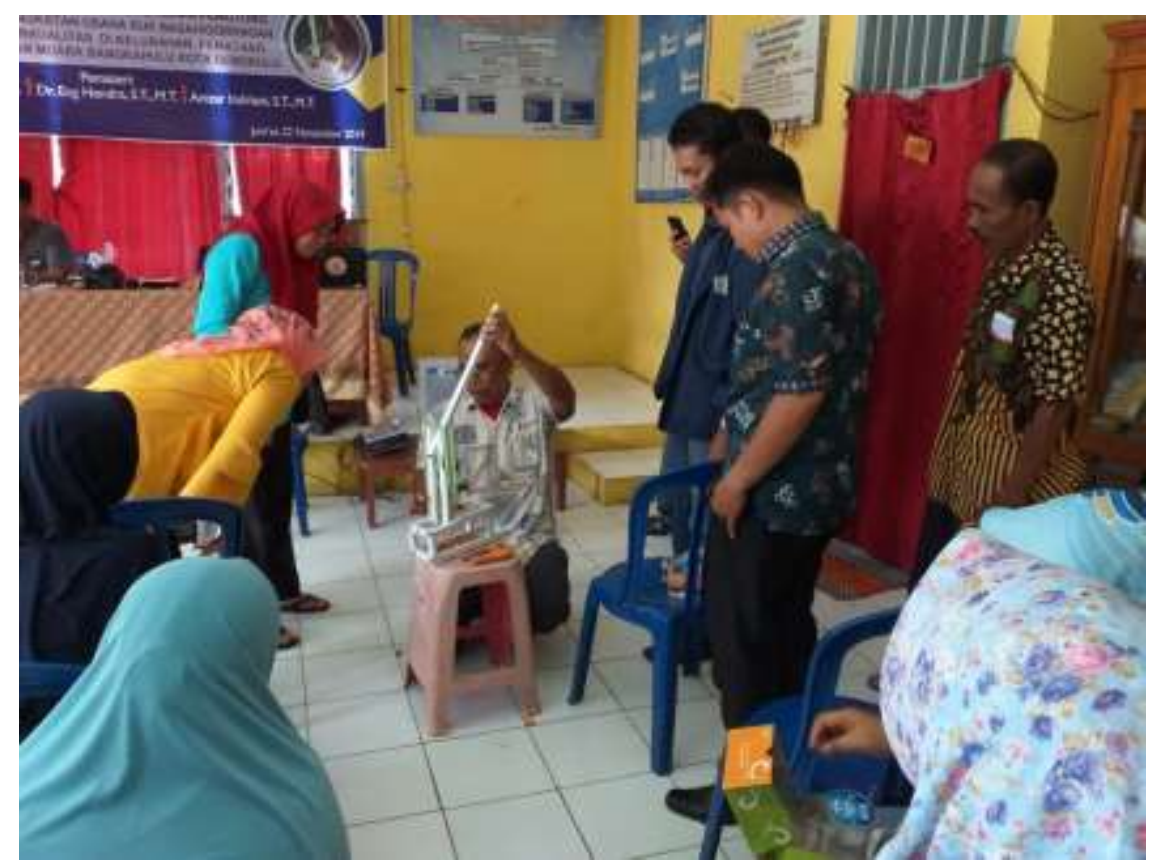

Gambar 9. Contoh Pengoperasian Alat

Setelah diajarkan mengunakan alat, peserta diminta untuk mencoba secara bergantian seperti terlihat pada gambar 10. Peserta diminta mempersiapkan sayuran/umbi-umbian yang akan dipotong, selanjutnya peserta diminta mengukur waktu dan kapasitas sayuran/umbi-umbian yang sudah terpotong yang akan dibandingkan hasil pemotongan dan pengukuran kualitas dari prosesmanual dan menggunkan mesin potong. Hasil uji coba penunjukkan bahwa dengan menggunakan alat tersebut, proses pemotongan lebih cepat dan hasil potong sayur/umbi jauh lebih rata .

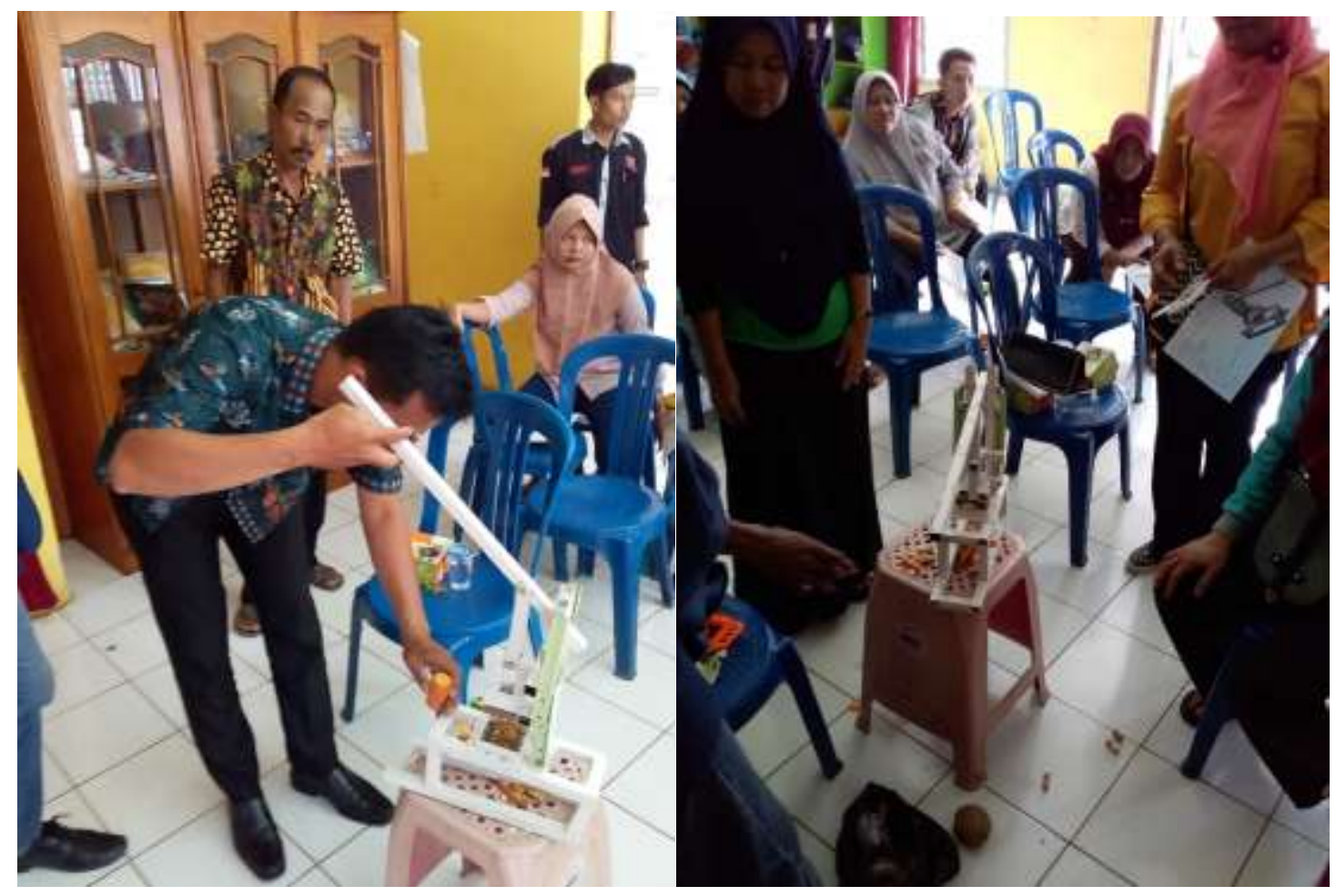

Gambar 10. Uji coba alat oleh peserta 
Setelah praktek uji coba alat, peserta diminta untuk memberikan tanggapannya tentang alat yang telah mereka rakit dan uji cobakan.

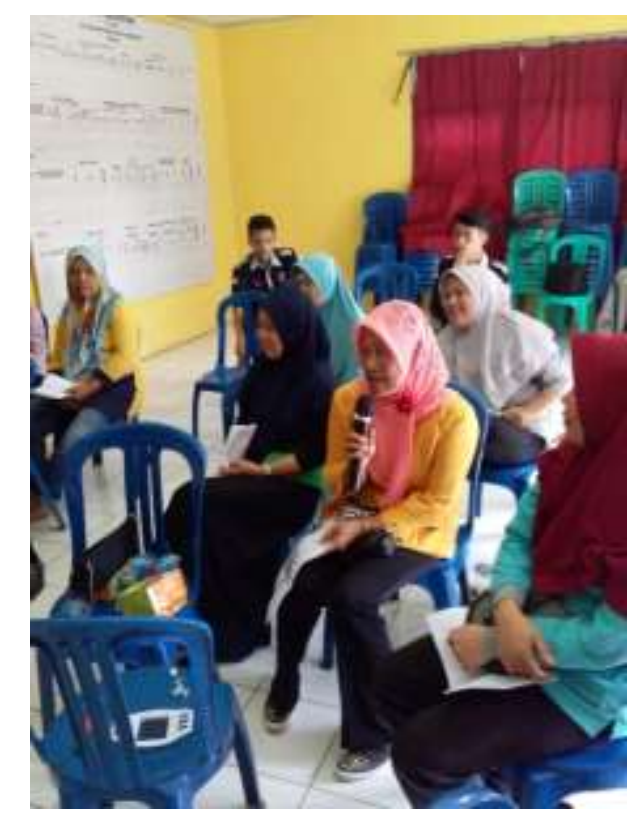

Gambar 11. Tanya Jawab

Peserta dengan antusias memberikan tanggapan tentang pelaksanaan kegiatan ini. Ini terlihat pada sesi tanya jawab seperti terlihat pada gambar 11. Mereka sangat tertarik untuk membuat dan mengaplikasikan peralatan tersebut. Keberlanjutan dari kegiatan ini sangat mereka harapkan. Salah satu peserta yakni Ibu Insasmi yang merupakan ketua RT 05, berharap agar kegiatan ini berlanjut dengan pelatihan pembuatan aneka bentuk cetakan pemotong sayur/umbi. Bentuk yang bervariasi mereka harapkan untuk tampilan lebih menarik.

Realisasi hasil pelaksanaan kegiatan pengabdian, fokus pada apa yang berubah dengan khalayak sasaran ketika sebelum dilakukan pengabdian dengan setelah adanya pengabdian, termasuk foto-foto kegiatan, data-data hasil yang diperoleh selama pengabdian, dan hambatan-hambatan yang dihadapi selama pelaksanaan kegiatan pengabdian.

\section{KESIMPULAN DAN SARAN}

Hasil kegiatan Pengabdian pada masyarakat ini menunjukkan bahwa peserta sangat tertarik untuk membuat dan mengaplikasikan peralatan tersebut. Keberlanjutan dari kegiatan ini sangat mereka harapkan. Salah satu peserta yakni Ibu Insasmi yang merupakan ketua RT 05, berharap agar kegiatan ini berlanjut dengan pelatihan pembuatan aneka bentuk cetakan pemotong sayur/umbi. Bentuk yang bervariasi mereka harapkan untuk tampilan lebih menarik.

\section{DAFTAR PUSTAKA}

Effendi, R., dan Khumaidi, M. , 2018, Perancangan Mesin Perajang Bawang Serbaguna Berpenggerak Motor Listrik Dengan Kapasitas 55 Kg/Jam, Jurnal Polimesin 16 (2) 
Lutfi, M., Setiawan, S., dan Nugroho, W., A., 2010, Rancang Bangun Perajang Ubi Kayu Pisau Horizontal. Teknik Pertanian, Universitas Brawijaya ISSN 0216-468. Jurnal Rekayasa Mesin 1(2): 41-46.

Mungkur, I. L. J., 2015. Rancang Bangun Alat Pengiris Kentang Spiral, Medan, Skripsi. Medan: Fakultas Pertanian, Universitas Sumatera Utara.

Mursidi, R. , 2015, Desain Perajang Serbaguna Dengan Tipe Blade Sliding dan Sistem Transfer Tenaga Semi Mekanis Dan Mekanis, Prosiding Seminar Agroindustri dan Lokakarya Nasional FKPT-TPI Program Studi TIP-UTM.

Saputra, M., Dicky, Herwandi dan Dharta, Y., 2012, Mesin Pemotong Singkong Kapasitas 120 kg/jam.Politeknik Manufaktur Negeri Bangka Belitung.Jurnal Manutech, 4 (2) 30 - 44 .

Shigley, JE, 1994, Perencanaan Teknik Mesin. Erlangga: Jakarta.

Stolk, J and Kros, C. 1997, Elemen Mesin Elemen Konstruksi Bangunan Mesin. Erlangga: Jakarta.

Sularso.2013, Dasar Perencanaan dan Pemilihan Elemen Mesin. Pradnya Paramitha: Jakarta.

Widiantara, T (2010. Effisiensi Pengirisan Bawang Merah Dengan Variasi Sudut Kemiringan Pisau Pada Alat Pengiris Bawang Merah Tipe Pengiris Vertikal, Jurnal Teknologi Pertanian 6(2): 60-64 